REVISTA DE DERECHO UNED, núm. 3, 2008

\title{
EL DERECHO DE INFORMACIÓN COMO GARANTÍA EN LA CONTRATACIÓN DE LOS CONSUMIDORES Y USUARIOS
}

\author{
Victoria Domínguez-Alcahud García-ATANCE
}

Sumario. Introducción.- I. El derecho de información de consumidores y usuarios en la Constitución Española.- II. La información veraz como derecho del consumidor y usuario.- II.A. Condiciones para que la información sea veraz: la veracidad como condición del lícito.II.B. Ámbito de la información.- II.C. La información como deber del empresario frente al consumidor.- III. La irrenunciabilidad del derecho de información de consumidores y usuarios.- IV. Conclusiones.

\section{INTRODUCCIÓN}

En 1978 apenas existía en España estructura alguna en la sociedad civil que se proyectara a la defensa del consumidor, como tampoco había administración pública destinada al servicio de tales necesidades $^{1}$. La antigua Ley 26/1984, de 19 de julio, General para la Defensa de los Consumidores y Usuarios ${ }^{2}$ puede ser considerada como el primer gesto político que pretendería desarrollar el artículo 51 de la Constitución Española, habiéndose sensibilizado la sociedad particularmente con motivo del desafortunadísimo suceso de la intoxicación motivada por el aceite de colza, que motivó más de 20.000 personas afectadas por tal envenenamiento y más de 600 muertes.

1 Lasarte Álvarez, C.: Manual sobre protección de consumidores y usuarios, $2^{\mathrm{a}}$ edic., Dykinson, Madrid, 2005, pág. 31.

${ }^{2}$ Boletín Oficial del Estado, de 24 de julio de 1984. 
Así, con el fin de "garantizar la defensa y consumidores y usuarios, protegiendo mediante procedimientos eficaces su salud, seguridad y sus legítimos intereses» (art. 51.1 CE), la Constitución insta a los poderes públicos a promover la información de los consumidores y usuarios ... en los términos que la Ley establezca» (art. 51.2 CE).

La antigua Ley General para la Defensa de Consumidores y Usuarios, al igual que hace la reciente promulgación RD Legislativo 1/2007,16 noviembre por el que se aprueba el Texto Refundido de la Ley General de Defensa de los Consumidores y Usuarios y otras leyes Complementarias ${ }^{3}$, pretendería de manera sucinta:

a) Definir los procedimientos concretos para la defensa eficaz de los consumidores y usuarios.

b) Delimitar el cauce legal que desarrollará en las mejores condiciones el ámbito del consumo en la sociedad.

c) Determinar los derechos y obligaciones que configuran la defensa y protección de consumidores y usuarios que deben ser respetados por las autoridades y poderes públicos.

d) Promover el desarrollo normativo futuro que garantice y favorezca la adecuada información de los consumidores y usuarios.

Desde esta perspectiva cabe afirmar que como los poderes públicos están sujetos a la Constitución y al resto del ordenamiento jurídico (art. 9.1 CE), quedan en consecuencia obligados a promover la información adecuada (art. 51.2 CE) a los consumidores para garantizar la defensa y protección de éstos en materia de contratación.

\section{EL DERECHO DE INFORMACIÓN DE CONSUMIDORES Y USUARIOS EN LA CONSTITUCIÓN ESPAÑOLA}

El Derecho de información, como derecho fundamental que contempla el art. 20 de la Constitución Española, es matizado por el art. $51.2 \mathrm{CE}$, al orientarse al ámbito de consumidores y usuarios, cuando se refiere a la adecuada información relativa al producto objeto de transacción comercial y que configura la base previa para la celebración correcta de un contrato, como afirma Cabanillas Sán$\mathrm{chez}^{4}$, «de manera que su ausencia o distorsión configuran, en gran

${ }^{3}$ Boletín Oficial del Estado, de 30 de noviembre de 2007

4 Cabanillas Sánchez, A.: La información al consumidor en la compraventa y arrendamiento de vivienda y el control de las condiciones generales, Madrid, 1994, pág. 63. 
medida problemas entre las partes contratantes o el empresario y consumidor».

A tal efecto, nuestro constituyente fue sensible a tal circunstancia cuando previó en el artículo $51 \mathrm{CE}$ las garantías precisas del consumidor en defensa de sus intereses legítimos, salud, y seguridad, a través de procedimientos idóneos orientados a tal fin; en consecuencia, cuando el precepto constitucional del art. $51 \mathrm{CE}$ : «Los poderes públicos fomentarán ...» adopta forma verbal futura, no sólo refleja el carácter imperativo del mandato constitucional, sino también el punto de partida que se orienta hacia el futuro en el desarrollo de la política de protección del consumidor y usuario.

De otra parte, el primer programa en materia de protección de los consumidores adoptado por la Comunidad Europea para definir una política de protección y formación o educación de los consumidores se sitúa en 1975, habiéndose sucedido desde entonces programas y resoluciones encaminadas al mismo fin, hasta ser reconocido en el Acta Única Europea la necesidad de un elevado nivel de protección del consumidor y usuario.

La Resolución del Consejo de Ministros de 15-12-1986 incorporó el reconocimiento de dicha política de integración, protección e información en el seno de las demás políticas de la Comunidad -medio ambiente, transportes, agricultura, etc.- al mismo nivel de prioridad, con las correspondientes consultas y representación de los consumidores a través del Comité Consultivo de los consumidores, de la Oficina Europea de Sindicatos y de la Comunidad Europea de Cooperativas de Consumo; por su parte, el constituyente español, al integrar la defensa de los consumidores y usuarios en el capítulo III de los principales rectores de la política social y económica, les dota de eficacia jurídica y vinculan a los poderes públicos, debiendo, en consecuencia —como afirma Torres del Moral ${ }^{5}$ - el poder político y el judicial informar su actuación en estos principios, y lo mismo cabe afirmarse de la Administración, sin cuyo servicio al Estado social, éste devendría ineficaz.

${ }^{5}$ Torres del Moral, A.: Principios de Derecho Constitucional Español, Servicio de Publicaciones de la Facultad de Derecho, Universidad Complutense, $3^{\mathrm{a}}$ edic., Madrid, 1992, pág. 570. 


\section{LA INFORMACIÓN VERAZ COMO DERECHO DEL CONSUMIDOR Y USUARIO}

Nuestro ordenamiento jurídico en materia de protección del consumidor dota de una serie de medios e instrumentos que, puestos a disposición de los consumidores, garantizan la correcta contratación de las partes: empresarios y consumidores. Así, el derecho a la adecuada información por parte del consumidor a que tiene derecho conforme el art. 51.2 CE: «los poderes públicos promoverán la información y educación de los consumidores y usuarios, fomentarán sus organizaciones y oirán a éstas en las cuestiones que puedan afectar a aquéllos en los términos que la ley establezca», se traduce e instrumentaliza en el ámbito de la sociedad de consumo, como afirma Lasarte ${ }^{6}$, no es, sino la publicidad, recibida en la actualidad por muy diversas vías y que además actúa como reclamo frente a los consumidores, por lo que hay que extremar rigurosamente las medidas de control sobre los índices de «veracidad en la oferta, promoción y publicidad", definidas en los artículos 2 y 3 del R.D. $515 / 1989^{7}$, cuando exigen que éstas deben ceñirse a las verdaderas características, condiciones y utilidad del bien, a fin de proteger al consumidor frente a la tentación de los empresarios de lograr atraer a clientes potenciales, a través de una información que no es veraz. En este sentido, el apartado segundo del artículo 3 es especialmente determinante en lo que afecta a las consecuencias de la exigencia de una información veraz como derecho de los consumidores y usuarios, en cuanto que faculta a estos mismos para exigir cuantos datos, características y condiciones se hubieran referenciado por el productor, para la comercialización el bien objeto del consumo, en vía publicitaria, «aun cuando no figuren expresamente en el contrato celebrado".

El artículo 8 de la antigua $\mathrm{LGDCU}^{8}$ extiende la aplicación del principio de veracidad a la oferta, promoción y publicidad de los bienes y servicios 9 . La obligación de veracidad está orientada a mejorar la posición contractual del consumidor, y no para empeorarla,

- Lasarte Álvarez, C.: Manual sobre protección de consumidores y usuarios, $2^{\text {a }}$ edic., Dykinson, Madrid, 2005, pág. 165.

7 R.D. 515/1989.

${ }^{8}$ LGDCU: 26/1984, de 19 de julio, Ley General de Defensa de los Consumidores y Usuarios.

9 Cabanillas Sánchez, A.: La información del consumidor en la compraventa y el arrendamiento de vivienda y el control de las condiciones generales, Instituto Nacional de Consumo, Ministerio de Sanidad y Consumo, Madrid, 1995, pág. 46. 
así si en el contrato se han pactado condiciones más ventajosas, éstas también serán exigibles; en este sentido, los consumidores y usuarios podrán exigir el contenido de dicha oferta, promoción y publicidad que integran el contenido del contrato, siendo ejercitable, tal como sostienen Corchero y Sandín ${ }^{10}$, como obligación contractual y de integración contractual, ya que el contenido del contrato no sólo lo forman las cláusulas y condiciones que figuran en el mismo sino también todo aquello reflejado en la oferta, promoción y publicidad, de donde se deduce la importancia que asume la información en la determinación del consentimiento a la hora de perfeccionar el contrato.

\section{II.A. CONDICIONES PARA QUE LA INFORMACIÓN SEA VERAZ: LA VERACIDAD COMO CONDICIÓN DEL LÍCITO}

Experimenta éste una limitación que expresamente refleja el art. 20.1.d) de la $\mathrm{CE}$ que es la de la información veraz. El contenido verídico de la información es contemplado en el mencionado artículo como «condición sine qua non para el lícito ejercicio» del derecho, erigiéndose por tanto como límite del ejercicio del derecho, lo que, en otras palabras, significa que la información falsa o errónea impediría el lícito ejercicio del derecho de información y del deber de información del empresario.

En este sentido, el Tribunal Constitucional ha tenido ocasión de manifestarse ${ }^{11}$, invocando el deber de dirigencia (Fundamento Jurídico 2) que debe presidir el ejercicio del profesional de la información para contrastar con datos objetivos la información de los hechos que transmite, dejando sin cobertura a quien actúe menospreciando la verdad y vulnerando, como señala Torres del Moral ${ }^{12}$, el derecho de otro sobre quien se vierten rumores o invenciones insidiosas, y el derecho de todos a recibir información veraz. Además, afirma el Alto intérprete constitucional: "para indagar si en un caso concreto el derecho a la información debe prevalecer será preciso constatar previamente la veracidad de los hechos y afirmaciones contenidos en esa información ${ }^{13}$.

${ }^{10}$ Corchero, M. y Sandín Mora, L., en Actualidad Administrativa, n ${ }^{\circ}$ 5, 29 enero-4 febrero 2001 .

11 STC 15/1993, de 18 de enero.

12 Torres del Moral, A.: «La libertad de comunicación pública. Sistemática constitucional y problemas generales", en El Derecho de la información, UNED, 2001.

13 STC 171/1990. Fundamento Jurídico 2. 
Así, la información obtenida lícitamente y con veracidad sí queda amparada - como afirma el Tribunal Constitucional — aun cuando su exactitud absoluta sea controvertible, ya que, como afirma el Tribunal Constitucional: «Si se impusiera la verdad como condición para el reconocimiento del ejercicio del derecho a difundir información, la única garantía de seguridad jurídica sería el silencion" ${ }^{14}$.

\section{II.B. ÁMBITO DE LA INFORMACIÓN}

La Ley 26/1986, de 19 de julio (RCL 1984, 1906), General para la Defensa de los Consumidores y Usuarios, consagra como un derecho básico de los consumidores y usuarios «la información correcta sobre los diferentes productos o servicios" y la educación o divulgación para facilitar el conocimiento sobre su adecuado uso, consumo o disfrute (artículo 2.1d), señalando expresamente que éste, junto con los demás derechos de los consumidores y usuarios, serán protegidos prioritariamente cuando guarden relación directa con productos o servicios de uso común, ordinario y generalizado (art. 2.2).

Por su parte, en su afán de garantizar una mayor claridad en la redacción y deseo integrador de ciertas lagunas que en la mencionada antigua Ley 26/1984,19 julio LGDCU había detectado la doctrina, en el Título I del RD Legislativo1/2007, 16 noviembre por el que se aprueba el Texto Refundido de la Ley General de Defensa de los Consumidores y Usuarios y otras leyes Complementarias, se procede a regular determinados derechos relativos particularmente a la información y formación y educación del consumidor y usuario.

En este sentido el artículo 17 del mencionado Texto Refundido establece en su apartado $1^{\circ}$ que los poderes públicos en el ámbito de sus respectivas competencias fomentarán la formación y educación de los consumidores y usuarios, asegurando que estos dispongan de la información precisa para el eficaz ejercicio de sus derechos y velarán para que se les preste la información comprensible sobre el adecuado uso y consumo de los bienes y servicios puestos a su disposición en el mercado.

De igual manera presta atención especial el Texto Refundido a la obligación que pesa sobre los medios de comunicación social de titularidad pública estatal, sobre los que hace recaer - tal como contempla el apartado $2^{\circ}$ del artículo 17 - la responsabilidad de dedicar

14 STC 6/1988. 
espacios y programas no publicitarios, destinados a la información y educación de los consumidores y usuarios. A este efecto determina que se faciliten en espacios y programas determinados, $\mathrm{y}$ atendiendo a su contenido y finalidad el acceso o participación de las asociaciones de consumidores y usuarios representativas, así como los demás grupos o sectores interesados en la forma que se acuerde con dichos medios.

En este sentido, hay que recordar que el artículo 2 del Real Decreto 515/1989, de 21 de abril ${ }^{15}$, ya definía que, sin perjuicio del cumplimiento de la Ley 34/1988, de 11 de noviembre, General de Publicidad, toda oferta, promoción y publicidad dirigida a la venta o arrendamiento de viviendas se ajustará a las «verdaderas características», condiciones y utilidad de la vivienda, expresando siempre si la misma se encuentra en construcción o si la edificación ha concluido.

Este artículo que preceptúa la veracidad en la información del objeto en cuestión, pretende proteger al comprador frente a posibles artimañas empresariales de promoción, tendentes a atraer la atención del consumidor como cliente potencial, como pone de relieve Bercovitz ${ }^{16}$.

En este sentido, la información proyectada concretamente en la esfera de la vivienda, es contemplada en el artículo 3.1 del R.D. $515 / 1989$, que insta a la información sobre el bien y además que sea veraz: «La oferta, promoción y publicidad dirigida a la venta (...) se hará de manera que no induzca ni pueda inducir a error a sus destinatarios, de modo tal que afecte a su comportamiento económico, y no silenciará datos fundamentales de los objetos de la misma».

Este apartado ciel legislador obliga a pensar no sólo en la obligación de dar información veraz, sino que, también prohíbe la omisión de la misma, como deber del empresario, de lo que tratamos a continuación.

Pero, como afirma Lasarte ${ }^{17}$, es particularmente en el apartado 2, del art. 3, donde se da un paso realmente importante y se pasa a la acción en cuanto a la protección del consumidor o usuario, ya que faculta al comprador o arrendatario de una vivienda para exigir cuantos datos, características y condiciones relativas a la construcción

15 RD 515/1989, de 21 de abril, BOE de 17 de mayo de 1989.

${ }_{16}$ Bercovitz Rodríguez-Cano, A.: "Modalidades especiales de venta y protección de los consumidores", en AA.VV.: Estudios jurídicos sobre protección de los consumidores, Madrid, 1987, pág. 159 y ss.

17 Lasarte Ảlvarez, C.: Manual ..., op. cit., pág. 166. 
de la vivienda, a su ubicación, servicios e instalaciones, adquisición, utilización y pago que se hubieren ofrecido por vía publicitaria «aun cuando no figuren expresamente en el contrato celebrado».

«Su contenido, las prestaciones propias de cada producto y las condiciones y garantías ofrecidas, serán exigibles por los consumidores aun cuando in fine no estén reflejadas en el contrato celebrado o en el comprobante recibido". Este artículo es complemento desarrollo de la LCU que en su art. 8.1 se expresa en términos generales, de forma idéntica, contemplando también la exigibilidad por parte del consumidor del contenido publicitario aun cuando no figurase en el contrato, documento o comprobante recibido; entendiéndose, además, que si el contrato celebrado contuviese cláusulas más beneficiosas, éstas prevalecerán sobre el contenido de la oferta salvo que, expresamente se acepten esos cambios por el comprador o arrendatario y los mismos se encuentren justificados por las circunstancias del caso.

Y no es otra la pretensión recogida según el artículo 61 del RD Legislativo1/2007, 16 noviembre por el que se aprueba el Texto Refundido de la Ley General de Defensa de los Consumidores y Usuarios y otras leyes Complementarias, cuando se hace referencia a que la oferta, promoción y publicidad de los bienes o servicios deberán ajustarse a su naturaleza, características o finalidad y a las condiciones económicas de la contratación; de igual modo que estima como exigibles por los consumidores y usuarios el contenido de la oferta, promoción o publicidad, así como las prestaciones propias de cada bien y sus garantías ofrecidas, aún en el supuesto de que no figuren expresamente en el acto celebrado o en el documento o comprobante recibido.

\section{II.C. LA INFORMACIÓN COMO DEBER DEL EMPRESARIO FRENTE AL CONSUMIDOR}

Los deberes de información en la fase de formación del contrato se fundamentan en la buena fe, aunque el código civil no contempla un deber general de información ${ }^{18}$. Este principio general del derecho obliga a los sujetos que establecen negociaciones a suministrar información sobre los hechos a los que se refiere el contrato que van a

18 Sin embargo, sí se encuentran supuestos concretos a lo largo del articulado del Código Civil, para el estudio de estos supuestos nos remitimos a Gómez Calle, E.: Los deberes precontractuales de información, La Ley, Madrid, 1994. 
celebrar, a fin de evitar el error en el que pudiera incurrir la otra parte contratante, lo cual se traduce en dos aspectos: uno positivo, el de transmitir la información exigible, y, otro negativo, el de abstenerse de dar información errónea al consumidor; en este sentido se ha manifestado Morales Moreno ${ }^{19}$ al reconocer el dolo como criterio de imputación de responsabilidad al vendedor.

Por su parte, las leyes especiales han ido estableciendo una serie de deberes legales de información en la fase de formación del contrato, otorgando el carácter de oferta vinculante dicha información y determinando el contenido mínimo de los contratos y la necesaria documentación por escrito, como es el caso de:

1. Ley 50/1980, de 8 de octubre, de Contratos de Seguros (LCS).

2. Ley $26 / 1991$, de 21 de noviembre, de Contratos celebrados Fuera de Establecimientos Mercantiles (LCFEM). Derogada por RD Legislativo1/2007, 16 noviembre, conforme a su Disposición Derogatoria Única.

3. Ley 7/1995, de 23 de marzo, de Crédito al Consumo (LCC).

4. Ley 21/1995, de 6 de julio, de Viajes Combinados (LVC). Derogada por RD Legislativo1/2007, 16 noviembre, conforme a su Disposición Derogatoria Única.

La Ley de Crédito al Consumo 7/1995, de 13 de marzo, refleja el interés del legislador en torno a las obligaciones de carácter informativo que recaen sobre el empresario en aras a proporcionar al consumidor toda la información posible de las ofertas de mercado.

De este modo se garantiza al consumidor una doble seguridad contractual, como señala Pous de la Flor ${ }^{20}$ :

- De una parte, la adquisición del máximo nivel de la información sobre el bien objeto de consumo en su fase precontractual en relación con las demás ofertas de mercado.

- De otra parte, la garantía de que la publicidad promocional del bien no induce a engaño.

Así, la información como derecho del consumidor se contrapone a la información como deber del empresario, consistente en facilitar al

19 Morales Moreno, A.: El dolo como criterio de imputación de responsabilidad al vendedor por los defectos de la cosa, ADC, 1982, pág. 631.

20 Pous de la Flor, P.: "Crédito al consumo», en Derecho Civil Comunitario, Colex, Madrid, 2006, pág. 374. 
comprador una documentación completa informadora sobre el bien, que, como señala el art. 13.2 de la Ley de Consumidores «debe responder a una información cierta, eficaz, veraz y objetiva».

Habiendo sido este artículo objeto de integración en el artículo 8 del RD Legislativo 1/2007,16 noviembre por el que se aprueba el Texto Refundido de la Ley General para la defensa de los Consumidores y Usuarios y otras leyes Complementarias, como veremos a continuación.

La información en la Ley General de Consumidores comporta, pues, doble perspectiva: desde la del consumidor, que calificamos como derecho del consumidor, a la que nos hemos referido anteriormente, y que emblemáticamente consagra el art. 51.2 CE, y el punto de vista del deber a tal información, que afecta a los suministradores de bienes y servicios, que ponen a disposición de los consumidores sus servicios.

Conforme a la Ley General de Consumidores, el art. 13, tratando de mejorar la posición de los consumidores, plantea sin duda alguna el tema como un derecho del consumidor y una obligación de los productores o empresarios, genéricamente considerados, en cuanto la información debe incorporarse a los propios bienes, productos o servicios.

Conforme al nuevo Texto Refundido este principio se concreta en el artículo 8 sobre los derechos básicos de los consumidores y usuarios entre los que reconoce como tales, entre otros, el de obtener información correcta - y por lo tanto veraz- sobre los diferentes bienes o servicios y la educación y divulgación para facilitar el conocimiento sobre su adecuado uso, consumo o disfrute.

Por otra parte, y concretamente para las entidades de crédito, establece el artículo 6 de la $\mathrm{LCC}^{21}$ una serie de obligaciones de carácter informativo tendentes a la protección del consumidor, tanto en fase precontractual como en fase contractual: deber informativo que preceptúa la LCC, definiendo toda la información posible sobre las distintas ofertas del mercado, que se concreta, como afirma $\mathrm{M}^{\mathrm{a}} \mathrm{Paz}$ Pous de la Flor ${ }^{22}$ con la publicidad de las distintas ofertas de crédito y la emisión de una oferta vinculante: 1995).

${ }^{21}$ Ley de Crédito al Consumo 7/1995, de 23 de marzo (BOE, 25 de mazo de

${ }_{22}$ Pous de la Flor, $\mathbf{M}^{\mathrm{a}}$ P.: "Crédito al consumidor», en Díaz-Ambrona Bardají, A.: Derecho Civil Comunitario ..., pág. 374. 
- La oferta vinculante se refleja en el art. 16 LCC, que obliga a que «el empresario que ofrezca un crédito a un consumidor estará obligado a entregarle antes de la celebración del contrato, si el consumidor así lo solicita, un documento con todas las condiciones del crédito, como oferta vinculante, que deberá mantener durante un plazo mínimo de diez días hábiles desde su entrega, salvo mediante circunstancias extraordinarias o no imputables a él».

- De esta manera, el legislador intenta evitar que el empresario haga una oferta tentadora para el consumidor y que luego no se mantenga.

- Por otra parte, la publicidad de las ofertas de crédito, definidas en el art. 17 de la mencionada LCC, establece las medidas necesarias que debe cumplir cualquier oferta vinculante, con carácter informativo para el consumidor, información además que no sea engañosa o desleal: "En la publicidad y en los anuncios y ofertas exhibidos en locales comerciales, en los que se ofrezca un crédito o la intermediación para la celebración de un contrato de crédito, siempre que indiquen el tipo de interés o cualesquiera cifras relacionadas con el coste del crédito, deberán mencionar también la tasa anual equivalente, mediante un ejemplo representativo».

\section{LA IRRENUNCIABILIDAD DEL DERECHO DE INFORMACIÓN DE CONSUMIDORES Y USUARIOS}

El derecho a la información tiene dos componentes que se pueden calificar de universalidad y generalidad, como diferencia Bel Mallén ${ }^{23}$, a través de los cuales se proyectan los mensajes informativos como vía para ejercer el derecho a la información. El primero de ellos hace referencia a la imposibilidad de excepción alguna a su ejercicio, por entender que ese carácter universal no admite ninguna clase de límites, mientras que el segundo, el de la generalidad, sí que admite que en determinadas circunstancias se pueda no limitar su ejercicio, sino exceptuar su ejercicio.

Y ello se explica porque, como señala el mencionado autor, no cabe aceptar ninguna excepción en lo referente a las personas que

${ }^{23}$ Bel Mallén, J.I.: "Derecho a la información y excepciones a los mensajes», en Derecho a la información, Ariel, Barcelona, 2003. 
son portadoras del derecho a la información, ya que todo individuo es portador del derecho a la información tanto lo ejerza como si no, de igual modo que tampoco puede ser restringido tal derecho en función de la clase de medio de comunicación de que se valga el empresario para proyectar tal información.

Los derechos de prestación entre los que se integra el art. 51.2 CE tienen contenido económico y se considera que sin ellos no puede alcanzar el ciudadano su desarrollo personal en las óptimas condiciones a las que aspira nuestro sistema constitucional social y democrático de derecho.

Estos derechos de prestación requieren una implicación del Estado en crear, mantener y fomentar las condiciones generales para el ejercicio de determinados derechos, sin las cuales tales derechos no podrán ser disfrutados por los ciudadanos, como señala Gómez Sánchez $^{24}$, en este sentido estos derechos se proyectan, además, tal como ha mantenido el T.C. ${ }^{25}$, "como elemento configurador del sistema político y, por ello, del Estado social y democrático de Derecho».

Pero, además de estas características, hay que mencionar que los derechos constitucionales, como derechos públicos subjetivos que son, responden a la posibilidad atribuida al individuo de poner en movimiento una norma jurídica en su propio interés», como afirma García de Enterría.

Pues bien, dadas las características de la Ley General para la Defensa de Consumidores y Usuarios 26/1984, de 19 de julio, que resumimos brevemente:

- Establecimiento de los procedimientos eficaces para defensa de los consumidores.

- Marco legal adecuado para promoción del movimiento asociativo del área.

- Declaración de principios, derechos y obligaciones orientados a la defensa y protección de consumidores y usuarios; todos ellos dirigidos, como vemos, a la protección del sector del consumo, es natural, como ha señalado Lasarte ${ }^{26}$, que uno de los criterios prioritarios de la Ley radique precisamente en garan-

${ }^{24}$ Gómez Sánchez, Y.: «Derechos y Libertades», en Lecciones de Derecho Político, UNED, Madrid, 1999, pág. 212. febrero.

${ }^{25}$ STC 49/1982, de 14 de julio. STC 40/1986, de 24 de enero. STC 34/1986, de 21 de

26 Lasarte Álvarez, C.: Manual ..., op. cit., pág. 36. 
tizar dicha protección, a través de la expresa declaración en la norma del art. 2.3, la irrenunciabilidad previa de los derechos y facultades otorgadas en ella, «la renuncia previa de los derechos que esta ley reconoce a los consumidores y usuarios en la adquisición y utilización de bienes o servicios, es NULA». Lo que no hace sino, de forma tácita, remitirse al artículo 6 del Código Civil.

Y por lo tanto no podría ser de otra manera la opción contemplada en el RD Legislativo 1/2007,16noviembre del Texto Refundido de la Ley General para Defensa de Consumidores y Usuarios y otras leyes Complementarias, al recoger en el Capítulo II del Título I destinado al Ámbito de aplicación y de Derechos básicos de los consumidores y usuarios, y específicamente la irrenunciabilidad de los derechos reconocidos al consumidor y usuario tal y como define en su artículo 10; cuando contempla que la renuncia previa a los derechos que esta norma reconoce a los consumidores y usuarios es nula, siendo asimismo nulos los actos realizados en fraude de ley, de conformidad con lo previsto en el artículo6 del Código Civil.

Este carácter irrenunciable del Derecho de información queda a su vez conformado por el art. 3.1 del R.D. 515/1989 de 21 de abril en la protección de los consumidores en cuanto al suministro de información en materia de compraventa y arrendamiento de vivienda.

A tenor de los cuales establece dicho artículo que «la oferta, promoción y publicidad dirigida a la venta o arrendamiento de viviendas se hará de manera que no induzca ni pueda inducir a error a sus destinatarios, de modo tal que afecte a su comportamiento económico, y no silenciará datos fundamentales de los objetos de la misma», lo que supone tácitamente la obligación de informar y no silenciar datos sobre el bien del consumo.

A tal efecto, conforme prescribe el art. 4 del Real Decreto, debe cursarse información tanto para el público como para las autoridades competentes, de los siguientes extremos: Quienes realicen las actividades sujetas a este Real Decreto deberán tener a disposición del público y, en su caso, de las autoridades competentes, la información siguiente:

1. El nombre o razón social, domicilio y, en su caso, los datos de la inscripción en el Registro Mercantil, del vendedor o arrendador.

2. Plano general del emplazamiento de la vivienda y plano de la vivienda misma, así como descripción y trazado de las redes 
eléctricas, de agua, gas y calefacción y garantías de las mismas, y de las medidas de seguridad contra incendios con que cuente el inmueble.

3. Descripción de la vivienda con expresión de su superficie útil y descripción general del edificio en el que se encuentra, de las zonas comunes y de los servicios accesorios.

\section{CONCLUSIONES}

Cabe, pues, en conclusión, afirmar en primer lugar que el derecho de información - y concretamente, de información veraz- se rebela como requisito indispensable para la eficacia juridica en materia de contratación de consumidores y usuarios con los empresarios, configurando un elemento o mandato de obligado cumplimiento para surtir efectos jurídicos una concreta relación contractual entre empresario y consumidores y usuarios, fuera de la cual dicha relación produciría efectos de nulidad contractual.

Pero, además, en segundo lugar, el derecho de información de los consumidores y usuarios respecto al producto objeto de relación contractual asume una especial condición o carácter garantístico de defensa y protección de consumidores y usuarios - como reconoce el artículo 51.1 CE-y que el constituyente hace recaer tanto en la figura del empresario o el productor, así como sobre los poderes públicos que están obligados a instar y promover la información de los consumidores y usuarios, como establece el artículo $51.2 \mathrm{CE}, \mathrm{y}$ máxima, en la medida en que éstos quedan sujetos - como define el art. 9.1 CE- a la Constitución y al resto del Ordenamiento jurídico, siendo así, labor de los poderes públicos, así como del empresario, velar porque tal condición garantística informativa se cumpla.

Y, finalmente, en tercer lugar, el derecho de información en el ámbito contractual entre consumidores y empresarios adquiere un carácter de universalidad que hace predicable y practicable su ejercicio, sin excepción alguna, ya que todo individuo es portador del derecho a la información - tanto si lo ejerce como si no-. Pero este derecho de prestación en el que se integra el art. $51 \mathrm{CE}$ tiene un contenido económico y se considera necesario para alcanzar el techo de Estado social al que aspira nuestro sistema constitucional, implicándose el propio Estado en esta tarea. Pues bien, en este contexto, hay que señalar que, dadas las características propias de la Ley General para la Defensa de Consumidores y Usuarios 26/1984, de 19 de julio, que el 
RD Legislativo 1/2007, 16 noviembre por el que se aprueba el Texto Refundido de la Ley General de Defensa de los Consumidores y Usuarios y otras leyes Complementarias asimismo ha hecho suyas, como son:

- procedimientos eficaces para la defensa de los consumidores,

- marco legal adecuado,

- declaración de derechos y obligaciones orientados a la defensa de los consumidores,

es natural que el criterio prioritario de la Ley sea garantizar dicha protección, con la expresa prohibición del artículo 2.3 de irrenunciabilidad del derecho, lo que comportaría el efecto de su nulidad, que corresponde al artículo 10, visto con anterioridad del RD Legislativo 1/2007, 16 noviembre por el que se aprueba el Texto Refundido de la Ley General de Defensa de los Consumidores y Usuarios y otras leyes Complementarias. 